their medical advisers, I have made myself acquainted with their after-histories, which have been on the whole extremely satisfactory. There have been three definite failures-one an acute case, where an insufficient quantity of serum was perhaps responsible, and two which relapsed after a period of some months' good health, and where there was every possibility of reinfection. Further operation had to be undertaken in all three cases, otherwise the results have been good. In spite of their dislike of subcutaneous injections many of the women have said they were glad to have them, as they felt the benefit. In nearly every case relief of pain was a marked feature. Seen after varying intervals of months the patients described them. selves as feeling splendid, being fit for anything, and able to do their own washing-in fact, they form a marked contrast to many other cases of gonorrhoeal infection where no serum had been given at operation, and where the presence of peritoneal adhesions causes so much pain and disability. In one case pregnancy was apparently proceeding normally. Discharges had stopped, and it was difficult to collect enough for bacteriological examinations, all of which were negative.

\section{Spectal Cases.} Case 1.

A good result was obtained by the intraperitoneal use of serum in the case of Mrs. B., the mother of two children, one a girl suffering from gonorrhoeal vaginitis, while the baby had ophthalmia neonatorum. There was a left-sided pyosalpinx oph an abscess in the pouch of Douglas. One tube and ovary and an abscess in the pouch of Douglas. One tube and ovary were removed, and closed without drainage. There was a very. the abdomen being closed without drainage. There was a very.
slight febrile reaction the night of operation; temperature $100^{\circ}$, slight febrile reaction the night of operation; temperature $100^{\circ}$,
pulse 90 . The patient made a good recovery. When seen eight pulse 90. The patient made a good recovery. When seen eight
months later she looked fit and well, and declared that she had months later she looked fit and
never been in better health.

Case 2.

Mrs. V. was a case of acute salpingitis, associated with metrorrhagia. The abdomen was opened, sero-pus mopped out of the pelvis, and the tubes washed with saline solution, but not removed. Serum was administered subcutaneously in saline. There was no febrile reaction. The result was excellent, and her doctor reports that her pelvic condition ten months and her doctor reports that her pel
vfter operation is most satisfactory.

Case 3.

Mrs. P. was a case of arthritis of the wrist occurring about the seventh month of pregnancy (primipara). There was a profuse cervical discharge. The patient was taken into hos pital and $20 \mathrm{c.cm}$. Of serum were given every few days subcutaneously in saline until $150 \mathrm{c.cm}$. had been given. One injection was made into the tissues round the wrist-joint and caused a marked local reaction, with redness and stvelling of the limb. This passed off, and both discharge and pain ceased. The baby was born in the maternity hospital and was quite healthy. Both mother and baby were seen some months later in the out-patient department in excellent condition; wrist movements were normal and lencorrhoea had ccased. In this case the patient had left her husband.

Case 4.

Another favourable result was in the case of Mrs. J., where there was a history of leucorrhoea extending over two years. After the birth of a child arthritis of the left lip developed and the patient was confined to bed. She was taken in to the maternity rest home for treatment, with her baby, aged 9 weeks. No gonococci were present, but her husband was also suffering from joint pains. Two subcutaneons injections of serum were given at an interval of eight days, each producing a very marked febrile reaction the same evening. The breast-fed baby also developed a serum rash. In this case the breast-fed baby also developed a serum rash. In this case the result was excellent. Pain ceased and the patient was able to
leave the home in about three weeks. When seen in the outleave the home in about three weeks. When seen in the out-
patient department three months later she could walk well, had patient department and was very pleased with herself.

C'ase 5.

In a chronic case of hydrosalpinx (MIrs. N., married six jears, husband a sailor, no children) both tubes were opened up. husband a sailor, no children doses of serum were given subcutaneously at intervals of Three doses of serum were given subcutaneously at intervals of forty-eight hours. There was a marked febrile reaction each
evening, the pulse being 116 and temperature $104.6^{\circ}$ on one evening, the pulse being 116 and temperature $104.6^{\circ}$ on ong
occasion. This patient was seen nine monthes iaver-ioritices clear, no discharge. She said she was in axcellent health.

\section{Case 6.}

Another case, Mrs. T., is interesting for the light it throws on obscure causes of puerperal infection. This patient had been under treatment during pregnancy for both gonorrhoea and under treatment during pregnaley fortment.

Before admission to the maternity home discharge had ceased for some weeks, and the Wassermann test was negative. The confinement was normal and was conducted under the strictest aseptic conditions, which include the shaving of the vulva and the wearing of gloves by all associated with the conduct of the labour. On the fifth day a rigor occurred, and the temperature rose to $102.8^{\circ}$, pulse 120 . The patient was anaesthetized and thoroughly examined, the uterus.being curetted and douched. It seemed so probable the uterus the case was curetted and douched. infection lighting up in the puerperium that at the same time I infection lighting up in the puerperium that at the same time I
gave $10 \mathrm{c.cm}$. antigonococcal serum with $10 \mathrm{c.cm}$. antistreptogave $10 \mathrm{c.cm}$. antigonococcal serum with $10 \mathrm{c.cm}$. antistreptococcal serum. The latter was given not because the case was
believed to be one of streptococal infection, but as a prophybelieved to be one of streptococcal infection, but as a prophy-
lactic against a secondary infection. Temperature and pulse dropped to normal, and the patient made a good recovery.

The diaguosis was confirmed by the presence of gonococci in the uterine discharge. There were no streptococci.

From such a limited number of cases I do not presume to draw any definite conclusions, but $I$ think these favourable after-histories warrant further experiment and study. I am hoping also to receive some assistance from bacterio. logical and immunity experts respecting the best method of administration of the serum, with regard to the site of the injections, their incidence, and the amount to be given. On theoretical grounds it is surprising that subcutaneous injections have been so successful, bearing in mind the nature of the microbe. Can one expect to reach an orgauism secreting an endotoxin by the blood stream, or must some other method be found by which it can be attacked locally?

Also, what is the explanation of the vigorous febrile reaction in chroric cases where subcutaneous injections have been used, while in the acute infections, where the tubes are pouring out pus, there is practically no febrile reaction either with the subcutaneous or intraperitoneal method?

In conclusion, I should like to take this opportunity of thanking Professor Nicolle of the Pasteur Institute for his lindness in placing so much valuable serum at my disposal; to Professor Beattie and his staff for numerous bacteriological examinations; and to Dr. Ruth Nicholson and my house-surgeons and sisters for their assistance with the notes and observations.

Rifrenencis.
1 Ivens: British Medical Jocrnal, June 19!h, 1909. 2 De Christmas: Annales Institut Pasteur, tome ix, No. 4, 1895. 3 Rogers and Tory: Journ. Amer. Med. Assoc., 1906, No. 4, p. 263. 4 Paraf : La sérotirérapie antigonococcique, Arnette, Paris, 1919. 5 Ivens : Burrish des Sciences July, th, 1919 . 7 Lumiere et Chevrotier: L a vie médicale. October $27 \mathrm{th}, 1920$.

\section{ALBUMINURIA IN RELATION TO LIFE ASSURANCE.: \\ BY}

\section{F. PARLES WEBER, II.D., F.R.C.P.}

Is the following remarks I shall deal only with albuminuria in youth and early adult life. From the point of view of prognosis and examinations for life assurance and appointments for clerkships, etc., I prefer to divide the subject under four main headings.

I.-Albuminuria Connected with Definite Nephritis, Chronic Heart Disease, Acute Frebrile Diseases, Amyloid Disease, and other Conditions, such as are met with in Hospital Wards and Ordinary Medical Practice.

These cases are well known, and in the present discussion we are not concerned with them, excepting in regard to so-called "residual albuminuria" following an attack of acute nephritis. As long as there is albuminuli: of this "residual" kind a life camnot be rogarced as up to the normal staudard; there inay still be a slumbering inflammatory process th the kidneys (one or both). Mere fonctiona! recovery in the general condition of a patient, with persistence of albuminuria, docs not mean that the life is a first class one any more than does functional recovery in a case of cardiac valvular disease with the persistence of a valvular murmur and cardiac hypertrophy. The extra amount to be placed on the life should depend on a variety of circumstances-for instance, the presence or absence of tube-casts, the amount of the lealiage of albumin, the results of various tests as to eflicient

* Read at a discussion on the subject at the Assurance Medical Society, January 5th, 1921 . 
functional activity of the kidneys, the length of time that the albuminuria has lasted, the blood pressure, and the condition of the caudidate in other respects.

\section{II.--Transient Albuminuria Due to Tarious Causes.}

Under this heading I would include cases of albuminuria rue to slight temporary nephritis and renal irritation, cases consected with dictetic errors, food idiosyncrasies, or the action of drugs, and cases of transient albuminuria caused by excessive muscular work. In many cases that I would place under this heading the precise cause of the albuminuria must remain uncertain, but the important point is that the albumin disappears rapidly and completely and that the general health is and remains good. In such cases several examinations are naturally often required before the life can be regarded as a first-class one.

III.-Postural or Orthostatic Albuminuria.

Under this beading I group the cases characterized by the occasional, but not invariable, presence of albumin (sometimes little, sometimes much) in the urine passed when the patient is up (that is to say, has been up for some time) but not in that passed when he is in bed or immediately after he has been lying for some time-for iustance, in that passed immediately after the night's rest on getting out of bed in the morning. The albuminons urine in these cases frequently contains an excess of "nucleo-albumin" or mucin," and not rarely calcium oxalate crystals are found on microscopic examination, and sometimes a few red blood corpuscles. "Cylindroids" in fair numbers are frequently observed, but the presence of true tube casts, excepting a few occasional hyaline casts (found with the aid of the centrifugal machine), should be re. gardect as suggesting some superadded renal irritation or

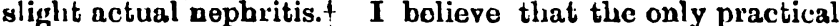
way to distinguish these cases in ordinary practice is to obtain samples of the candidate's urine passed imme. diately after getting out of bed in the morning. In genuine cases these samples of urine should be found to be quite free from albumin. It is an unfortuate mistake occasionally made to speak of the "morning urine" in cases of orthostatic albuminuria being free from albumin, for it is precisely the urine passed at about $100^{\prime}$ clock in the morning which may be especially albuminous. For practical purposes I think that what is called "lordotic albuminuria" (L. Jehle and others) should be regarded as a variety of orthostatic albuminuria in which a decidedly lordotic position of the body acts as an essential and determining (though not the only essential) cause of the albuminuria.

In the discussion on the after-history of cases of albuminuria occurring in adolescents, which took place on May 2nd, 1911, at the Medical Section of the Royal Society of Medicine, I made some remarks on the favour. able prognosis in such cases, $\$$ and said that I did " not think that albumiuuria occurring in apparently healthy adolescents could justly be regarded as belonging to any other class than orthostatic albuminuria, unless it could bc definitely ascertained that the urine passed immediately on getting out of bed after the night's rest contained albunin." If anything, I am now still more convinced that in un. complicated cases of orthostatic alburninuria the life may be regarded as a normal one from the life assurance point of view. Moreover, no young person should be prevented from living an ordinary active life merely because of the presence of orthostatic albuminuria. Indeed, for these cases an active life-as much as possible in the open air, without over-fatigue-is probably the best. True ortho. static albnminuria may occasionally be met with up to 25 to 30 years of age (and possibly even later in life). In some way or other it is often connected with the tall

* A trace of nucleo-albumin in the urine passod inmediately on getting out of bed in the morning must not be mistaken for albumin I The brachial systolic blood pressure in these cases is in general. 1 think, islightly below rather than above the average.

(ifle artificial lordosis) is sufficient in some subjects to induce temporar afblininuria., This favonrs the view that in cases of "orthostalic about but ris th not leakage of albumin in the uri po when the aftected individual tets uftera night's rest.

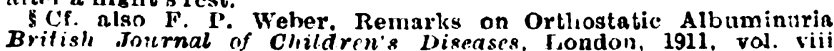
pp. $395-390$. In this paper I referred to individual cases I luad met
with. "lanlyy" build of body suggestive of visceroptosis; it has been much irritten about, cspecially by Continental anthors, and, as every doctor now lnows, is frequontly associated with, and excited by lordosis (Jehle). There is nothing surprising in the fact that it may occasionally exist in association with true nephritis (for instance, after scarlatina). and that it may be met with in the subjects of tuberculosis, syphilis, etc. The few post. morlem examinations that have been recorded tell us nothing more than this. It seems, indeed, quite natural that, occurring, as orthostatic albuminuria not rarely does, in "orergrown" children and in tall, fiat. chested and often lordotic adolescents, it should be occa. sionally associated with early pulmonary tuberculosis. I have observed orthostatic albuminuria in two young men with grave forms of congcnital heart disease.: Dr. Mackenzie Wallis has kindly informed me that in the albuminuric case to which le referred-a man in whom albuminuria was present for thirteen years without apparently harming him until at last he died at the age of 30 years from uraemia - the albuminuria was not of the orthostatic type, and was almost certainly due to a true chronic nephritis.

In regard to prognosis (and life assurance) in cases of adolescent albuminuria help can doubtless be obtained from a chemical examination by estimating the relative proportions of scrum-albumin and globulin in the urine, + but it is of at least as great importance to ascertain whether the albuminuria conforms to the orthostatic type-whether albumin is altogether absent from the urine passed immediately on getting out of bed in the morning-though this latter investigation may give rise to considerable inconvenience if the examinee cannot bo trusted.

\section{5.-The Presence of Albumin (frequently only a trace)} accompanying Minute Quantities of Pus, Blood, or Semen in the Lirine.

The slight opacity in the urine due to the presence of minute quantities of pus or blood, or pus and blood, in the urine may easily be overloolsed, or wrongly neglectod as of no importance, in examinations for life assurance or appointments such as clerkships, etc. (Naturally in the case of females a difficulty is more likely to arise owing to admixture of the urine with vaginal or slight loucor. rhoeal discharge.) The haze which calls for a microscopic examination may be not more than that due to the presence of bacteria in urine from cases of bacteriuria or in urine which is decomposing. I do not know how it compares with the opalescence which, according to Mackenzie Wallis, may exceptionally be observed in urines containing an excess of euglobulin.: Whenever it is evident by the ordinary tests that an opacity (however slight) in the urino is not due to phosphates (or, after cooling, to urates), a

F. T. Waver, Congenital Heart Disense. with Extreme Secondary Polycythaemia and Orthostatic Albuminuria, Edinburgh Nedice cournal 10. Ner Hedicine clinical Hed ic

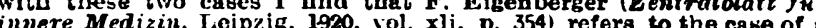
che Medizin. Leipzig. 1920, Vol. Yli, p. J54) refers to the case of a young man with polscy thaemia rubra secondary to cardiac disease stntic (lordotic) alluminuria "ras discovered : a lordotic position of his body caused bis abundant cylindroids. 1 . Mr. Mackenzie Wallis tells me that though there was well marked globulinuria in tilis case, the patient was observed to have pufiness presstire was constantly. $160 \mathrm{lmm}$. Hg, and red blood cells (though no tube casts) were found in the urinary doposit. The case has boen described in full by Ir. Ivor. J. Davies, Lancet. 1920, ii, $\mathrm{p} .1249$. ('f. R. W. Macliterie Wallis, Non-nenhritic Albuninuria. Procced-
ings of the Royal Society of Medicine, Section of Medicine, 1920, rol. $x$ iii, pp. 96-104.

S Mackenzie Wallis (loc. cit.. p. 100) writes: "In my opinion euglobulin is really globulin which has associatcd with it a small lecithin-globulin isolated from pseudo-chylous effusions, the degreo of opalescence depending on the amount of associated lipoids. This euglobulin is precipitated by acetic acid in the cold, and is, in my excess of this euglobulin containing excess of lipoids. either in the blood plecral, pericarlial or peritoneal effasions, or in the urine gives rise to a marked opalescence, and when this globulin is gives rise then the malescence diseppears " wackenzie willis in a case described hy Bramwell and Paton (1892), in which actually the urine snontaneously deposited rhombic crystals of globnlin. In regard to rseudo-chy'lous effusions cf. also Mackenzie Wallis and gcbölberg. Quarterly, Journal of Medicine. Oxford, 1910, vol. iii, 1) 301 : Mackenzio Wallis Frocedings of the Royal Society of Medicin
1913, vol. vi. p. 13 ; anct H. A. Lediard, Ibid., p. 123. 
microscupical examination (oven a hasty one, without waiting for a sediment to form and without the help of tho centrifugal machine) may prove of extreme value. At examinations for appointments and life assurauce the discovery of minute quantities of blood, not sufficient to produce any reduish coloration of the urine; may lead to the detection of renal tuberculosis, as in tho case of a young man whoin I recently examined for a clerkship. In such cases the correct diagnosis must of course be con. firmed by special examinations, such as by cystoscopy aud by catheterizing the ureters, to see if only one lidiney is affected. On repeated examinations in cases of this class the urine may sometimes be found apparently fiec from albumin (by the ordinary boiling and acidifying test) though its slight opacity when freshly passed silıould lead to a microscopical examination being made. On rare occasions, in such cases, even the slight obrious opacity may temporarily be absent from urine, which by micio. scopical examination of the centrifuge sediment is found to contaiu miunte quantities of blood or pus.

I nudcrstand from Dr. Lister (though I have not observed it myself) that the urine at the commencement of au attack of gonorrhoea (congestive stage) may sometimes contain a little albumin eren before the appearance of any purnlent discharge.

After the subsidence of an attack of hacmaturia of unccrtain causation the presence of a little pus in the urine by microscopical examination may indicate grave disease, such as a faalignant tumour involving the pelvis of one lii]ney. $\because$ This ivhole subject, however, I need not further discuss kere.

\section{OY THE ACTION OF CERTAIN SPECIAL PRI: PARA'IOYS ON MALARIAL PARASITES AND THEIR EMPLOYMEN'T IN 'THE 'TREA'TMEN'I OF MALARIA.}

$$
\text { Br }
$$

II.sJor J. PRATT.JOHNSON, M.C., D.A.D.M.S.(PathologY),

MaJOR IENNETH GILCHRIST, M.C., AND

Captain HAY-MICHEL, S.A.M.C.

These investigations were carried out at No. 4 General Hospital, S.A.M.C., Roberts Heights, during 1917-19 on malarial patients invalided from the German East African cumpainn. The majority of the cases were of a severe type, associated with marked anaemia and debility, numerous relapses occurring in hospital while under quinine treatment (25 to 30 grains daily). Of 8,788 hospital cases 61 per cent. showed benigu tertian parasites in their peripheral blood, 23 per cent. malignant subtertian, 16 per cent. both benign tertian and malignant subtertian varasites. The average period in hospital and convalescent cainp of these cases was fifty-one days, during which time the blood was examined at weekly intervals and the patients kept on routine daily quimine treatment. ParasitoJogical relapses occurred during this period of observation in 24 per cent. of the benign tertian cases, 11 per cent. of the malignant subtertian cases, and 39 per cent. of the mixed infections. The circumstances under which these cases contracted malaria (a particularly strenuous military campaign in the tropics) suggested a special terminology to meet this resistant clinical condition-namely, "cam. paign malaria," which apparently owes its intractability to repeated reinfection associated with severe physical strain in unacclimatized individuals only partially protected from a tropical climate and frequently insufficiently supplied with suitable food.

The frequency with which relapses occurred and the slowness with which these patients recovered a condition of good health emplrasized the importance of testing any

* In one such case, a man, aged 33 years, under my observation in 1918, the patient (owing to some mistake) was forced to join the arm but was soon transferred to a military hospital and then set free. He died in Marchi, 1920, and the post-nortem examination showed malignant trmour and pyonephrosis of the left kidney, with secondary cumours elsewhere in the body. This was Case 17 in a paper which I Published (in regard to anotber subject) in the Intcruational Clinics, remedy which might cut short the period of treatment necessary and reduce tho number of relapses. Accordingly these investigations were initiated, with the object of pro. viding if possible a more effective treatment. It is not proposed to deal in this paper with the comparative studies made of the results of trentment of different infec tions with vaying doses of quinine administered by the oral, intramuscular, and intravenous rontes. The practical outcome of this work, however, was the adoption of a stanclard treatment for' all arerage cases of malaria. 'This treatment consistel of 30 grains of quinine in solution by the mouth daily for three weeks, followed by 20 grains daily for one month and subseduently 10 graius daily for two montlis.

Neo-salvarsan, Silvarsan, Neo-mirarsivin, hiharsivas, GiLYI.

In view of the debilitated condition of many of the cases selected for treatment it was necessary to exercise the grentest care in the employment of these toxic preparations. Accordingly the patients were specially preparci, and the dose of the "606" preparations employed was invariably about half that doso commonly used for the treatment of syphilis (neo-kharsivan, neo-salvarsan, 0.45 gram; salvarsau, kharsivan 0.3 gram; galyl 0.2 gram).

Until some experience of these preparations had been obtained in malarial patients it was customary at first to give intravenous injections at weekly intervals. Subsequently, howerer, it was found that intravenous injections conld with safety be given on alternate days for three or four injections, and in one of the cases reported in this series fourteen intravenons injections of 0.2 gram galyl were administered during an inclusive period of twentytwo days, as many as five injections being given on successive days without any obvious harnful effects.

During the past three years some thonsands of intravenous injections of these preparations have bcen administered in malarial subjects without a single fatality. It is therefore clear that the employment of intrarenous injectious of the above preparations in malarial subjects is not attended by any appreciable or special risk, provided the doses and methods recommended are used and the precantions enumerated are fully observed.

Apart from the general contraindications in regard to the employment of these preparations commonly recounized when considering the treatment of syphilis, it is necessary specially to consider the following points in regard to the employment of these preparations in malarial subjects.

(a) Tachycardia and Dilitation.-These are symptoms of the disease resulting from anamia and toxaemia. 'They improved, however, rapidly as a result of intravenous injections of salvarsun and galyl, and in 154 cases subjected to this treatment, the majority of whom bad some cardiac embarrassment, not a moment's anxiety on this scorc was experienced.

(b) Pyrexia.-Some observers have held that following an injection of " 606 " or galyl the temperature often rises 1 to 1.5 degrees, sometimes accompanied with slight rigor, nausea, and vomiting as part of the general reaction to the drug. In a series of orer 790 injections these plicnomena were observed only seven times with the above doses.

(c) Renal Complications.- Is these drugs are toxic, it is necessary for the patients' safety that they should be eliminated fairly rapidly. Where, therefore, there is a history of recent nephritis, or where the symptoms of such a condition are present (albumin, oedema, etc.) an injection should not be given.

(d) Gastro-intestinal Conditions.-As vomiting is also a fairly frequent symptoris of reaction after injection, severo vouiting, diarrhoea, or obstinate constipation slould be corrected before an injection is given.

\section{Preparation of the Patient.}

Sufferers from malaria should have cornplete rest in bed for at least twenty-four hou's before an injection. 'Their diet should be light and easily digested during this period. 'The bowels should be opened either by a purgative pill (for example, pil. lyydrarg. coloc. co. with liyose.) the previous night, followed by saline (mist. alba) the following morning or by an enema in the moruing before injection. A light brealrfast - one egg, two slices of toast, and one cup of ten-giren at least four hours before injection, may be allowed, but no food should be 